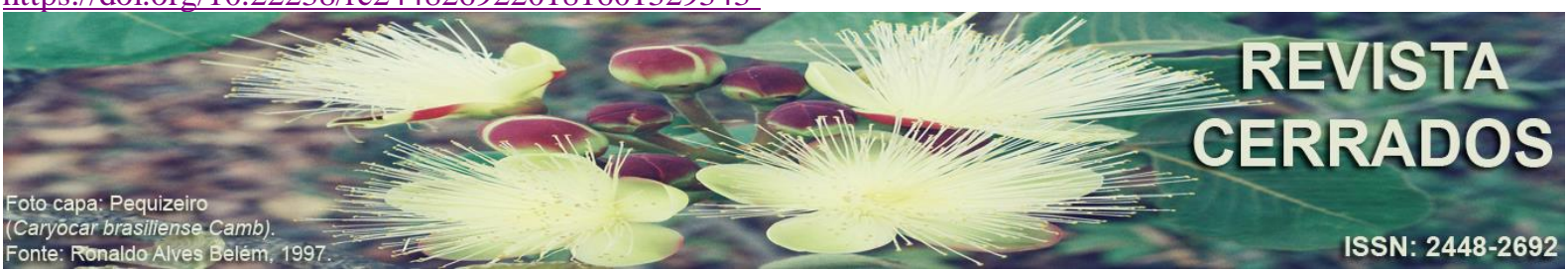

\title{
ANÁLISE DA ACESSIBILIDADE DA POPULAÇÃO DA CIDADE DE MONTES CLAROS/MG À UMA ESCOLA PÚBLICA POR TRANSPORTE COLETIVO
}

\section{ANALYSIS OF THE ACCESSIBILITY OF THE CITY POPULATION OF MONTES CLAROS / MG TO A PUBLIC SCHOOL FOR COLLECTIVE TRANSPORTATION}

\section{ANÁLISIS DE LA ACCESIBILIDAD DE LA POBLACIÓN DE LA CIUDAD DE MONTES CLAROS / MG A UNA ESCUELA PÚBLICA POR TRANSPORTE COLECTIVO}

\author{
Narciso Ferreira Santos Neto \\ Universidade Estadual de Montes Claros - UNIMONTES \\ E-mail: < narciso_santos1@yahoo.com.br>. \\ Rodrigo Marques do Nascimento \\ Universidade Estadual de Montes Claros - UNIMONTES \\ E-mail:<rodrigo.m.jesus@hotmail.com>. \\ José Luiz Lopes Teixeira Filho \\ Universidade Federal de Juiz de Fora - UFJF \\ E-mail: <jluiztx@terra.com.br>.
}

\section{RESUMO}

As cidades médias se destacam pelo seu caráter dinâmico, centralizador, atrativo de mercadoria, serviços e pessoas. A cidade de Montes Claros, localizada no norte de Minas Gerais, tem demonstrado tais características através do intenso fluxo de viagens demandado pela população aos Polos Geradores de Tráfego. Nesse cenário, necessita-se de um modo capaz de suprir a carência de transporte das pessoas, de maneira segura, econômica, sustentável e racionalizando. O ônibus, gerido por meio de diretrizes do Estado, se apresenta como melhor opção em relação aos automóveis particulares, uma vez que reduzem congestionamento e exercem papel social. Nessa perspectiva, o presente trabalho analisa a acessibilidade por transporte público coletivo ao polo gerador de tráfego (Escola Estadual Professor Plínio Ribeiro), localizado na Avenida Mestra Fininha, número 1225, bairro Jardim São Luiz, em Montes Claros - MG. Essa análise leva em conta o tempo de viagem (tempo de espera e tempo de percurso) por transporte público com ligação direta a escola e utiliza Sistemas de Informações Geográficas para armazenamento, processamento e espacialização

Licenciada sob Creative Commons (cc) $1 \mathrm{Er}-\mathrm{h}=\mathrm{H}-\mathrm{C}$
Revista Cerrados, Departamento de Geociências e Programa de Pós-Graduação em Geografia (UNIMONTES) 
SANTOS NETO, N. F.; NASCIMENTO, R. M.; TEIXEIRA FILHO, J. L. L.

Análise da acessibilidade da população da cidade de Montes Claros/MM à uma escola pública por transporte coletivo

dos dados coletados. A partir daí, sugere-se o nível de acessibilidade dos moradores da cidade de Montes Claros à escola Estadual Professor Plínio Ribeiro, o qual se mostrou com melhores resultados na área central e, quase sempre, reduziu-se à medida que se aproximava das regiões periféricas.

Palavras-chave: Cidades Médias. Transporte Público Coletivo. Acessibilidade. Montes Claros.

\begin{abstract}
Medium cities stand out for their dynamic character, centralizer, attractive merchandise, services and people. The average city of Montes Claros, located in the north of Minas Gerais, has shown such feature by intense displacement flow demanded by the population Polos traffic generators. In this scenario, you need is a modal capable of filling the transport of persons, safe, economical, sustainable and rational manner. The bus, operated by state guidelines, is presented as the best option in relation to private cars, since they do not cause congestion and exert social role. In this perspective, this paper analyzes the service by public transportation to the pole traffic generator (State School Professor Plinio Ribeiro), located on the promenade Master Slim, number 1225, São Luiz Jardim, in Montes Claros - MG. This analysis takes into account the travel time (waiting time and travel time) by public transportation with direct connection to school and uses Geographic Information Systems for storage, processing and spatial distribution of the data collected. From there, it is suggested that the level of accessibility of the residents of the city of Montes Claros State Teacher Plinio Ribeiro school.
\end{abstract}

Keywords: Medium Cities. Collective Public Transport. Accessibility. Montes Claros.

\title{
RESUMEN
}

Las ciudades medias se destacan por su carácter dinámico, centralizador, atractivo de mercancía, servicios y personas. La ciudad de Montes Claros, ubicada en el norte de Minas Gerais, ha demostrado tales características a través del intenso flujo de viajes demandado por la población a los Polos Generadores de Tráfico. En este escenario, se necesita de un modo capaz de suplir la carencia de transporte de las personas, de manera segura, económica, sostenible y racional. El autobús, gestionado por medio de directrices del Estado, se presenta como mejor opción en relación a los automóviles privados, ya que reducen congestión y ejercen papel social. En esta perspectiva, el presente trabajo analiza la accesibilidad por transporte público colectivo al polo generador de tráfico (Escuela Estadual Profesor Plínio Ribeiro), ubicado en la Avenida Maestra Fininha, número 1225, barrio Jardim São Luiz, en Montes Claros - MG. Este análisis tiene en cuenta el tiempo de viaje (tiempo de espera y tiempo de recorrido) por transporte público con conexión directa a la escuela y utiliza Sistemas de Información Geográfica para almacenamiento, procesamiento y espacialización de los datos recolectados. A partir de ahí, se sugiere el nivel de accesibilidad de los habitantes de la ciudad de Montes Claros a la escuela estatal, el profesor Plínio Ribeiro, el cual se mostró con mejores resultados en el área central y casi siempre se redujo a medida que se acercaba a las regiones Periféricos. 
SANTOS NETO, N. F.; NASCIMENTO, R. M.; TEIXEIRA FILHO, J. L. L.

Análise da acessibilidade da população da cidade de Montes Claros/MM à uma escola pública por transporte coletivo

Palabras clave: Ciudades Medias. Transporte Público Colectivo. Accesibilidad. Montes Claros.

\section{INTRODUÇÃO}

A expansão urbana aliada à urbanização são fenômenos comuns e responsáveis por inúmeras alterações na estrutura das cidades médias brasileiras. Essas mudanças ocorrem nos setores econômicos com a atração de indústrias, serviços e mercadoria e no âmbito social com o intenso fluxo de pessoas de cidades circunvizinhas à procura de emprego, lazer e serviços especializados. Nota-se, portanto, que devido ao seu dinamismo essas cidades apresentam intenso fluxo populacional, gerando demanda por transporte no meio urbano.

Para atender a sociedade, o Estado utiliza do transporte público coletivo, uma vez que consegue atingir a população em geral, não provoca congestionamentos e, via de regra, possui valor acessível para todos. Além disso, visando regulamentar e organizar esse tipo de transporte, o Estado cria legislações como o Estatuto da cidade, de ordem nacional e o Plano Diretor, sendo este último na esfera municipal, para garantir o direito ao transporte para todos.

Para que esse sistema de transporte seja de qualidade é necessário controlar algumas variáveis, como: tempo de caminhada até o ponto de embarque, tempo de viagem e tempo de caminhada do ponto de desembarque até o destino final. São elas que, basicamente, definem o nível de acessibilidade do transporte em questão. Nessa perspectiva, o presente trabalho busca analisar a acessibilidade de moradores na cidade de Montes Claros por meio da utilização de transporte público coletivo para deslocamento diário para Escola Estadual Professor Plínio Ribeiro, também localizada neste município.

\section{CIDADES MÉDIAS E TRANSPORTE PÚBLICO COLETIVO}

As cidades médias se destacam no cenário atual brasileiro pelo seu papel dinâmico, centralizador, por reunir atividades ligadas ao setor terciário, como educação, saúde, mão de obra especializada, grandes redes de supermercados, hospitais, universidades e também devido a atividades relacionadas ao setor secundário, como indústrias de alimentos, remédios e vestimentas. Além disso, pode-se perceber o seu papel de intermediação entre as 
SANTOS NETO, N. F.; NASCIMENTO, R. M.; TEIXEIRA FILHO, J. L. L.

Análise da acessibilidade da população da cidade de Montes Claros/MM à uma escola pública por transporte coletivo

pequenas e grandes cidades o qual impõe reconhecimento e importância na estruturação da rede urbana. (BELTRÃO SPOSITO, 2004).

Nota-se, a partir disso, que essas cidades apresentam grande fluxo de pessoas, serviços, mercadorias e informações, graças à desenvolvida estrutura urbana que possuem, permitindo a população local e circunvizinha solucionarem suas demandas de saúde, alimentação, educação superiores e de serviços especializados. Para tanto, a necessidade por transportes é alta e deve ser sanada. O meio optado pela população é a compra de automóveis particulares como, carros e motos. Porém esses trazem relevantes impactos ao trânsito e acaba por gerar novos problemas de mobilidade. Percebe-se que:

\begin{abstract}
A erosão das cidades pelos automóveis provoca uma série de consequências tão conhecidas que nem é necessário descrevê-las. A erosão ocorre como se fossem garfadas - primeiro em pequenas porções, depois uma grande garfada. Por causa do congestionamento de veículos, alarga-se uma rua aqui, outra é retificada ali, uma avenida larga é transformada em via de mão única, instalam-se sistemas de sincronização de semáforos para o trânsito fluir rápido, duplicam-se pontes quando sua capacidade se esgota, abre-se uma via expressa acolá e por fim uma malha de vias expressas. Cada vez mais solo vira estacionamento, para acomodar a um número sempre crescente de automóveis quando eles não estão sendo usados (JACOBS, 2001, p. 389)
\end{abstract}

Por outro lado, a opção por transporte coletivo oferece inúmeras vantagens, como: diminuição da poluição urbana e dos congestionamentos e maior disponibilidade de solo urbano que provavelmente estariam sendo usados com função de estacionamento. Ademais, esse sistema de transporte exerce um solidário papel social, já que, por um preço econômico, promove acesso para a população, sobretudo, aos de baixa renda. Nesse sentido:

\footnotetext{
Ele pode ser o melhor instrumento para a requalificação urbana das cidades. (...) Ao se estabelecer uma política de desenvolvimento ambiciosa, que considere importante a valorização dos espaços públicos e sua retomada para os pedestres, o transporte público aparece com todas as suas vantagens. A recuperação das áreas verdes, hoje comprometidas para estacionamentos, o aumento da acessibilidade às áreas centrais adensadas e as áreas destinadas exclusivamente a pedestres, tudo isto pode ser garantido pelo transporte público, que organizado em rede, deve assegurar o acesso a todos equipamentos de interesse coletivo, como universidades, centros esportivos e culturais, museus e parques, além dos locais de trabalho (ANTP, 2001, p.5).
}

Além disso, segundo a ABNT na NBR 15570-2011 os ônibus tipo padron tem capacidade para de carregar 80 pessoas em pé e sentados, substituindo em tese cerca de 80 automóveis que carregam, geralmente, uma só pessoa, raramente carrega duas. Por conseguinte, um ônibus, mesmo sem grandes aparatos tecnológicos irá emitir menos 
SANTOS NETO, N. F.; NASCIMENTO, R. M.; TEIXEIRA FILHO, J. L. L.

Análise da acessibilidade da população da cidade de Montes Claros/MM à uma escola pública por transporte coletivo

poluentes que um automóvel, se considerados o seu potencial poluidor, dividido pelo número de pessoas que transporta. Assim, o transporte coletivo polui muito menos que um automóvel (BRANCO, 1990).

Nessa perspectiva, tendo em vista esses proveitos, faz-se necessário haver um sistema de transporte público coletivo apto para oferecer deslocamentos seguros, acessíveis e confortáveis para a população. O Estado, ciente dessa carência, cria aparatos legais para garantir o acesso e disponibilidade de transporte para todos. No Estatuto das Cidades (Lei $\mathrm{n}^{\circ}$ 10.257/2001) que, dentre outros, discorre sobre as funções sociais das cidades, impõe no art. 2, inciso I a concretização do direito ao transporte para a população.

No âmbito municipal, tem-se o Plano Diretor que é responsável por definir diretrizes para organização e implantação da infraestrutura e dos serviços de transporte coletivo urbano, consoante aos anseios e prerrogativas do Ministério Público e da sociedade. Essa legislação é obrigatória para os municípios com população superior a vinte mil habitantes e também exerce papel fundamental no ordenamento do crescimento urbano. Porém para que esse dispositivo legal cumpra sua finalidade é fundamental haver um contínuo planejamento que antecipe soluções para o futuro e revisões periódicas visando atualizar e mantê-lo a par do crescimento da cidade (SIEBERT, 1998).

Dessa forma, respaldado legalmente, o transporte público deve ser implantado com finalidade de cumprir sua função social, gerando mobilidade e acessibilidade para a população. O termo acessibilidade não deve ser restringido apenas a fatores físicos, quais sejam, por exemplo, vagas reservadas para gestantes e idosos e acesso de cadeirantes ao transporte urbano. Numa visão holística, Brasil (2007, p. 42-43) define acessibilidade como:

A condição do indivíduo se movimentar, locomover e atingir um destino almejado, 'dentro de suas capacidades individuais', isto é, realizar qualquer movimentação ou deslocamento por seus próprios meios, com total autonomia e em condições seguras, mesmo que para isso precise de aparelhos específicos. Nesse sentido, a acessibilidade é antes de tudo, uma medida de inclusão social.

O presente trabalho analisa acessibilidade como a facilidade de utilizar o serviço de transporte urbano, configurado pelo tempo de percurso até o ponto de embarque, tempo de espera nesse ponto, tempo de viagem no transporte público e o tempo de caminhada do desembarque até o destino final. A soma desses tempos constitui-se o tempo de deslocamento. (FERRAZ; TORRES, 2004). 
SANTOS NETO, N. F.; NASCIMENTO, R. M.; TEIXEIRA FILHO, J. L. L.

Análise da acessibilidade da população da cidade de Montes Claros/MM à uma escola pública por transporte coletivo

Cunha e Silva (2010), ao se tratar de tempo de deslocamento para usuários de serviços de saúde especializados indica que esse tempo deve ser de 30 minutos para ser considerado satisfatório; entre 30 e 60 minutos, qualidade intermediária e acima de 60 minutos, insatisfatória. (SANTOS NETO 2015) também utiliza esses dados para desenvolver trabalho sobre acessibilidade a unidades de saúde em Montes Claros. Neste estudo, ainda que analise a acessibilidade a uma instituição de ensino, toma como base os índices de Cunha e Silva (2010), uma vez que também existem limitações no tempo de caminhada dos usuários do transporte público em questão, por se tratar de crianças e adolescentes.

\section{METODOLOGIA}

Para esse estudo de caso, foram georeferenciado, por meio de um dispositivo de GPS (Global Position System), todos os pontos de embarque e desembarque de transporte coletivo urbano da cidade de Montes Claros. Esses dados, juntamente com o centroide das edificações da cidade georeferenciados e do trajeto das linhas de ônibus que possuem ligação direta à escola Plínio Ribeiro, utilizou-se o Softwares TransCAD para alocar essas informações. O tempo médio de percurso foi o principal resultado da alocação. Através dele, inferiu-se o intervalo de tempo gasto de todas as residências da cidade a escola Professor Plínio Ribeiro que foi comparado com os índices de acessibilidade sugeridos pela bibliografia utilizada. Esse dado também foi normalizado (Figura 1), transformado numa escala de 0 a 1 e empregado para indicar o nível de acessibilidade, de acordo com a estratificação 1 (Excelente), 0,75 a 0,99 (Ótimo), 0,5 a 0,75 (Bom), 0,25 a 0,5 (Regular), 0,01 a 0,25 (Ruim) e 0 (Péssimo). Por fim, através Software ArcMap, esses dados foram especializados e representados por meio de mapas.

Essa metodologia baseou- se em Santos e Neto (2015), no que tange a escolha de variáveis a serem analisadas para indicar o nível de acessibilidade. A escolha da função depende da natureza do atributo que está sendo normalizado. Cada um dos atributos considerados teve a sua própria função de pertinência definida de modo a representar os resultados da coleta de dados. Considerou-se o valor de pertinência 1 como a melhor situação de acessibilidade, e o valor 0 como a pior situação. O gráfico de normalização do tempo de 
viagem generalizado no veículo foi definido com base nos resultados do valores máximos admissíveis para este atributo.

Assim sendo, $\mathrm{t}=$ tempo de viagem no veículo (em minutos) e $\mu=$ valor normalizado: a) se $\mathrm{t}<=30 \rightarrow \mu=1$; b) se $30<\mathrm{t}<=60 \rightarrow \mu=-0,0333 \mathrm{t}+2$; c) se $\mathrm{t}>=60 \rightarrow$ $\mu=0$. A curva de pertinência estabelecida também é uma curva decrescente (quanto maior o tempo de viagem, menor o nível de acessibilidade). Essa curva pode ser interpretada do seguinte modo: um indivíduo que gaste um tempo de até 30 minutos para chegar à escola tem um bom nível de acessibilidade (função de pertinência igual a 1). Um usuário que tenha que viajar por mais de 60 minutos tem um nível de acessibilidade ruim (função de pertinência igual a 0). Entre 30 e 60 minutos (pontos de controle mínimo e máximo), a variação é gradual, de acordo com a função definida.

Figura 1 - Normalização do tempo de deslocamento

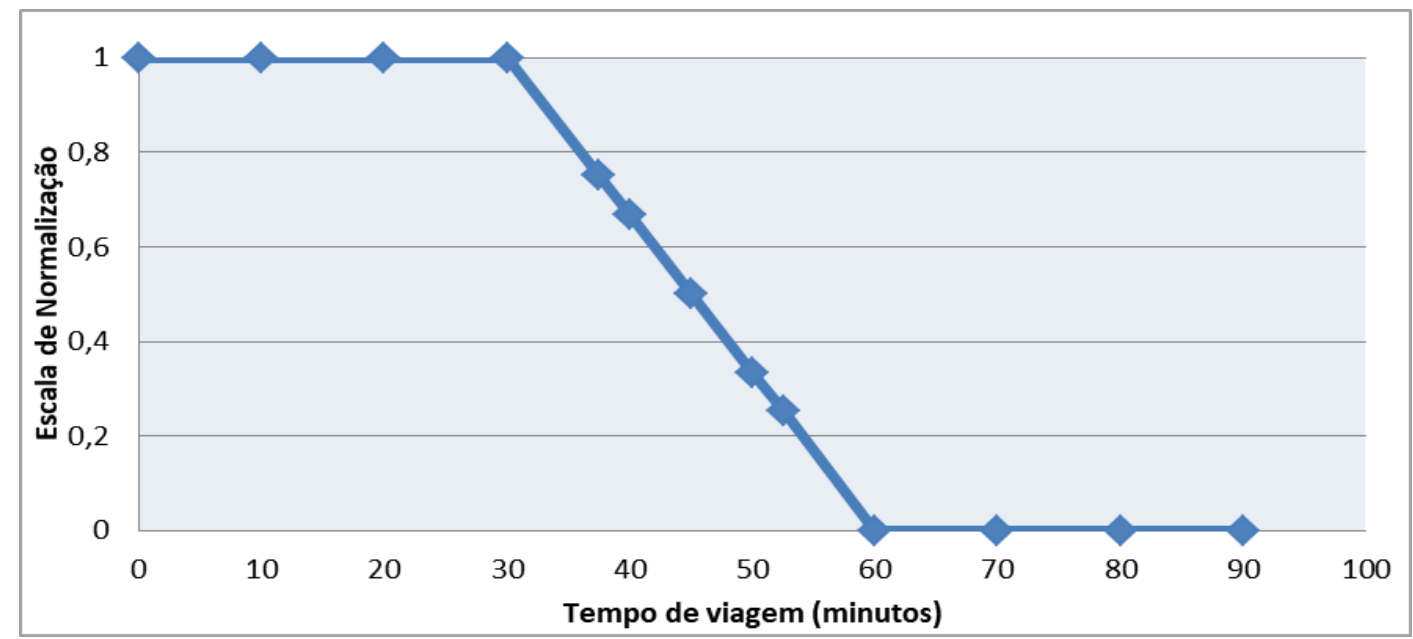

Fonte: Autoria própria.

\section{RESULTADOS E DISCUSSÕES}

A cidade de Montes Claros está situada no Norte de Minas Gerais, dispondo área da unidade territorial de $3.568,941 \mathrm{~km}^{2}$ e população estimada em 390.212 mil de pessoas. (IBGE, 2014). No que se refere à economia, Montes Claros apresenta um PIB a preços correntes no valor de 4.860 .942 bilhões de reais. (IBGE, 2011).

A partir da década de 1970 essa cidade média começa a acelerar seu processo de expansão urbana com a chegada de indústrias e o fortalecimento das atividades de comércios 
SANTOS NETO, N. F.; NASCIMENTO, R. M.; TEIXEIRA FILHO, J. L. L.

Análise da acessibilidade da população da cidade de Montes Claros/MM à uma escola pública por transporte coletivo

e prestação de serviços. Atualmente, esse processo de expansão urbana em Montes Claros ainda continua em amplo crescimento, Corroborando para o fluxo mais intenso de pessoas, que demandam por mobilidade no espaço urbano.

Mapa 1: Localização da Cidade de Montes Claros/ MG

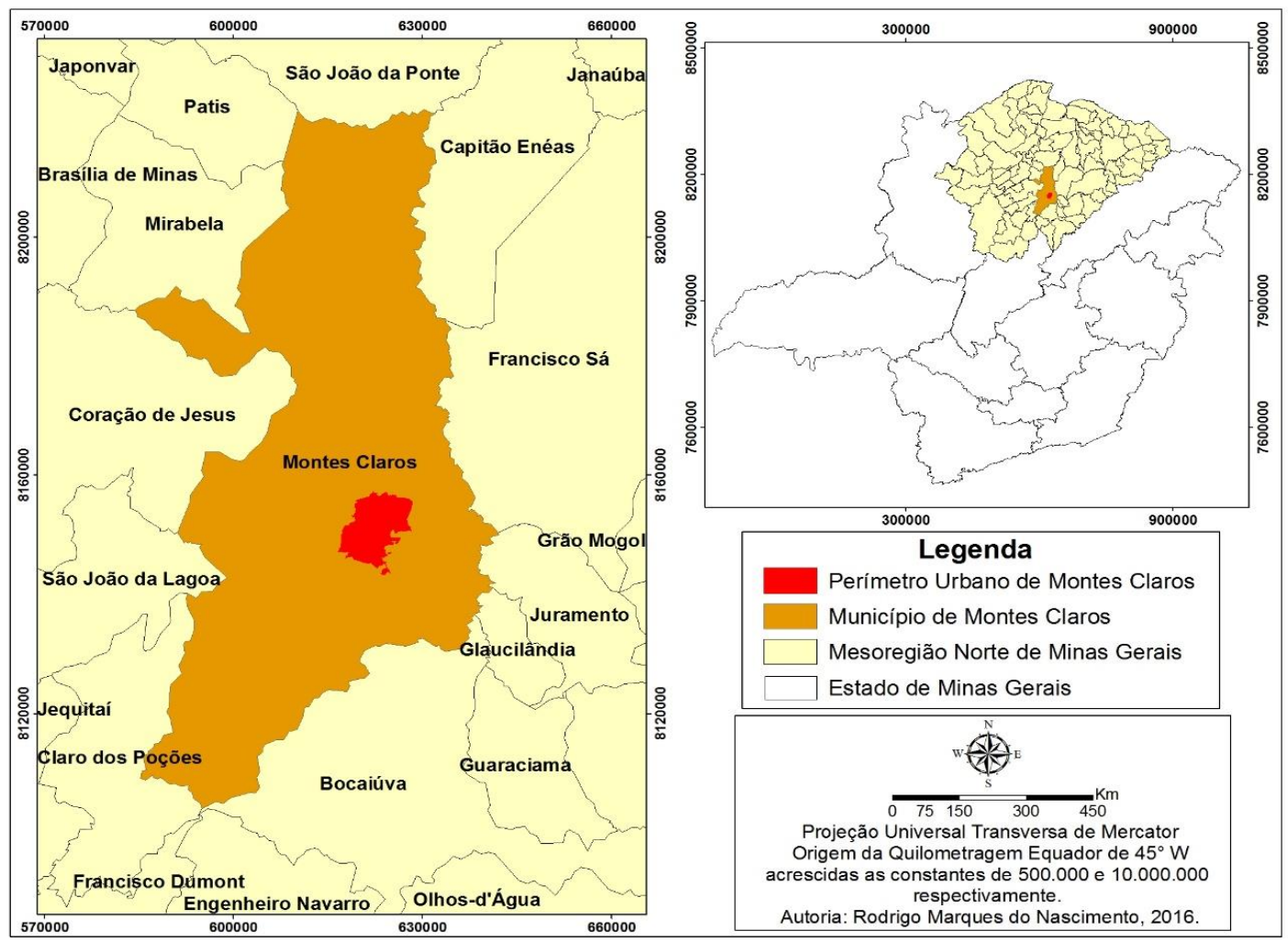

Fonte: Autoria própria.

Nesta cidade está localizada a Escola Estadual Plínio Ribeiro, especificamente, na avenida Mestra Fininha, número 1.225, bairro Jardim São Luiz. Essa instituição, mais antiga do Norte de Minas foi fundada em, 1879, para se tornar referência no ensino público na região. Atualmente conta com mais de 3.500 alunos divididos em ensino fundamental e médio conforme superintendência regional de ensino de Montes Claros. A Escola Estadual Plínio Ribeiro foi escolhida para estudo por abrigar estudantes de todas as regiões da cidade e por ser o segundo educandário público estadual em numero de estudantes matriculados.

Do ponto de vista da engenharia de transporte, esse estabelecimento estudantil é considerado um Polo Gerador de Tráfego (PGT). Segundo Rede Ibero-Americana de Estudo em Pólos Geradores de Tráfego (2005) uma instalação é considerada um PGT quando o 
SANTOS NETO, N. F.; NASCIMENTO, R. M.; TEIXEIRA FILHO, J. L. L.

Análise da acessibilidade da população da cidade de Montes Claros/MM à uma escola pública por transporte coletivo

desenvolvimento de suas atividades exerce grande atrativo sobre a população, gera grande número de viagens e, consequentemente, causa reflexos diretos na circulação viária.

Nesse cenário, na busca de se estimar a acessibilidade à escola Plínio Ribeiro, analisou-se quais linhas de ônibus público coletivo apresentavam trajeto com ligações diretas e estavam em pleno funcionamento e disposição a população local. Identificaram-se cinco linhas, a saber: 5801 (Vila Sion/ Vila Mauricéia - Via Ibituruna), 5802 (Vila Sion 2/ Rodoviária), 5803 (Santa Lúcia/ Sapucaia), 1901 (Unimontes/Amazonas - Via Conservatório) e 8201 (Morada do Parque/ UFMG). Ao todo, elas atendem diretamente um percentual de $42,5 \%$ dos bairros da cidade. Estes, localizados majoritariamente nas Regiões Central, Oeste e Leste de Montes Claros.

Dentre essas regiões, a Oeste, próxima à escola Plínio Ribeiro, destaca-se por apresentar pontos de embarque e desembarque das cinco linhas especificadas acima, o que contribui com o aumento da acessibilidade temporal e geográfica dos moradores dessa região ao local em estudo. Na perspectiva da distância de percurso, a linha 1901 se aponta como a de menor extensão, com apenas 8,3 quilômetros, sendo a de menor itinerário entre as linhas analisadas. Com valores intermediários, estão as linhas 5802 e 5803, possuindo 13,6 e 14,6 quilômetros, respectivamente.

As linhas 8201 e 5801 são as que apresentam maiores extensão entre o ponto de partida e o ponto de chegada, ambas com aproximadamente 16 quilômetros. Por um lado, por possuírem maiores percursos, provocam maior abrangência na área de atendimento, fazendo com que mais pessoas sejam atendidas pelo modal. Por outro lado, implicam quantidades elevadas de pontos de paradas, o que aumenta o tempo de ciclo dessas linhas, abaixa o grau de efetividade e ocasionam viagens longas, diminuindo o índice de acessibilidade para os passageiros.

Nesse sentido, constatou-se que as linhas 1901, 5802 e 5803 possuem os menores tempos de ciclo, sendo uma hora, uma hora e quarenta minutos e uma hora e trinta minutos, respectivamente. Já as linhas 5801 com tempo de ciclo de duas horas e 8201 com duas horas e dez minutos evidenciaram tempo de ciclo elevado, se comparadas com as demais linhas estudadas. Dado isso, para diminuir a frequência das linhas, são disponibilizados pela operadora de transporte do município mais de um ônibus por linha e, em horário de picos, o incremento é ainda maior. 
SANTOS NETO, N. F.; NASCIMENTO, R. M.; TEIXEIRA FILHO, J. L. L.

Análise da acessibilidade da população da cidade de Montes Claros/MM à uma escola pública por transporte coletivo

Mapa 2: Linhas de ônibus coletivo com ligação direta a Escola Estadual Professor Plínio Ribeiro

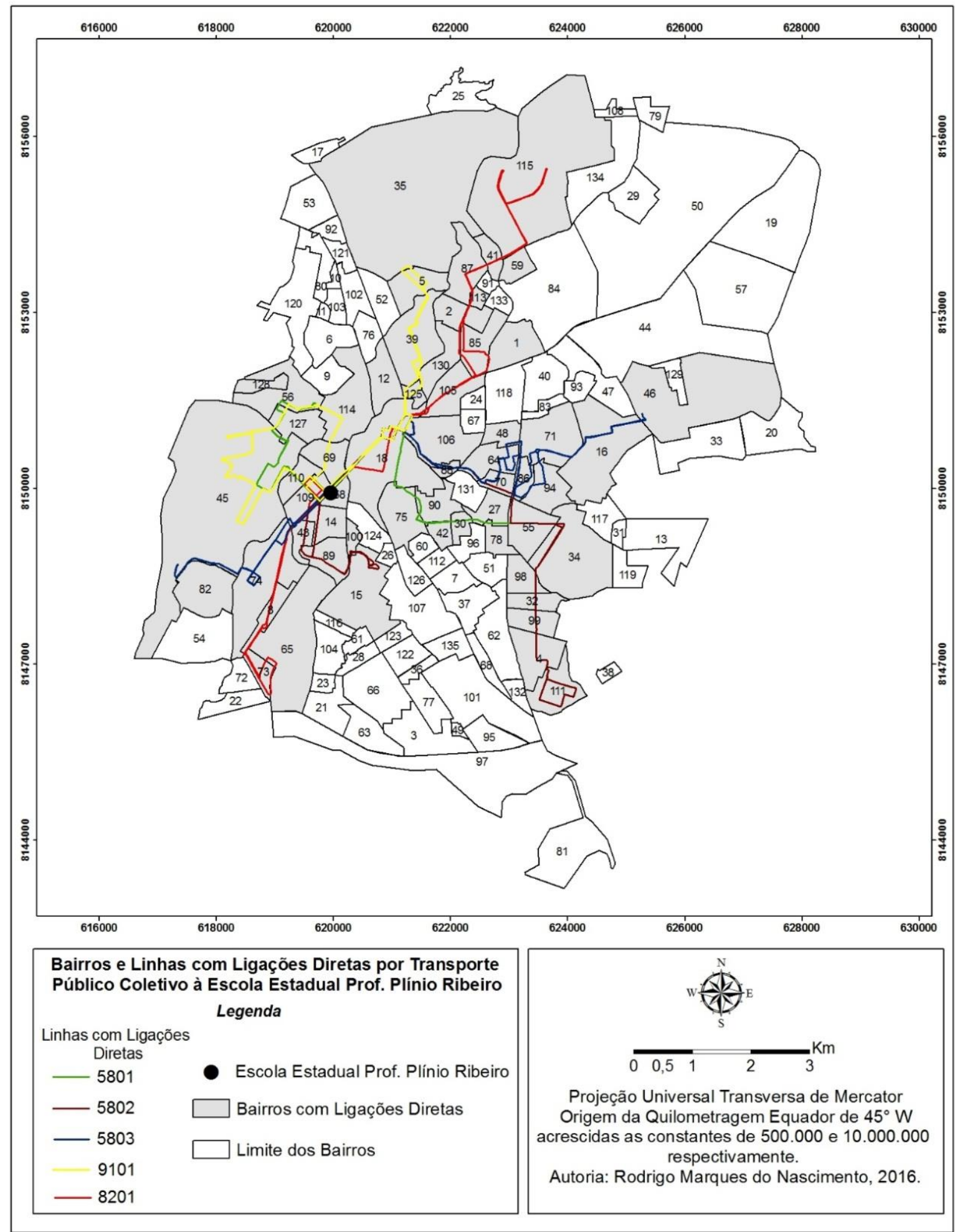

Fonte: Autoria própria. 
SANTOS NETO, N. F.; NASCIMENTO, R. M.; TEIXEIRA FILHO, J. L. L.

Análise da acessibilidade da população da cidade de Montes Claros/MM à uma escola pública por transporte coletivo

Através da figura 3 se observa o nível de acessibilidade dos moradores da cidade de Montes Claros à Escola Estadual Professor Plínio Ribeiro. Nota-se que a área central apresenta os melhores índices de acessibilidade, uma vez que estão em um raio de 1,5 quilômetros de distância da escola, conta com a avenida Mestra Fininha como via de escoamento rápido e possuem cinco linhas com ligação direta ao estabelecimento estudantil.

À medida que se afasta da área central, ocorre redução significativa da acessibilidade, saindo de acessibilidade total (excelente) para regular e ruim. Essa queda é explicada pela elevada distância de caminhada até o ponto de embarque, predominante, por exemplo, nos bairros São José, Roxo Verde, Morrinhos, Melo, Todos os Santos, Santo Expedito e Vila Guilhermina.

A região Oeste, composta pelos bairros Ibituruna, Morada do Sol, Morada do Parque, Augusta Mota, São Norberto e Jardim São Luiz que é o bairro de localização da escola Plínio Ribeiro se configura como região de bom desempenho de acessibilidade, devido a presença da avenida Santos Guimarães, avenida Doutor João Chaves, avenida Corinto Crisóstomo Freire e, principalmente, a avenida Mestra Fininha. Esta possui extensão de aproximadamente 3,5 quilômetros e perpassa toda a zona Oeste.

Em relação a região Norte, constituída pelos bairros Santa Cecília, Vila Tiradentes, Renascença, Floresta, Planalto, Jaraguá, Village do Lago e Alcides Rabelo, se destacou pelos baixos índices de acessibilidade a escola Plínio Ribeiro. Nota-se que apenas alguns bairros dessa região são servidos com a linha 8201, o que ainda assim, não garante índices de acessibilidade satisfatórios, uma vez que o tempo de viagem até a instituição de ensino é alto.

A região Sul, embora possuam bairros com localização próxima ao polo gerador de tráfego em estudo apresentou baixos índices de acessibilidade, visto que possui reduzidos níveis de serviço de linhas com ligações diretas a escola. Dentre os bairros com essa característica, pode-se citar: Maracanã, São Judas Tadeu, Vila Campos, Santo Inácio e Alterosa. Por fim, a Região Leste destacou-se por apresentar níveis de acessibilidade excelente e ótimo, refletindo o elevado nível de serviço das linhas que atuam nessa área, a saber: 5801, 5802 e 5803. 
SANTOS NETO, N. F.; NASCIMENTO, R. M.; TEIXEIRA FILHO, J. L. L.

Análise da acessibilidade da população da cidade de Montes Claros/MM à uma escola pública por transporte coletivo

Mapa 3: Nível de acessibilidade à Escola Estadual Professor Plínio Ribeiro

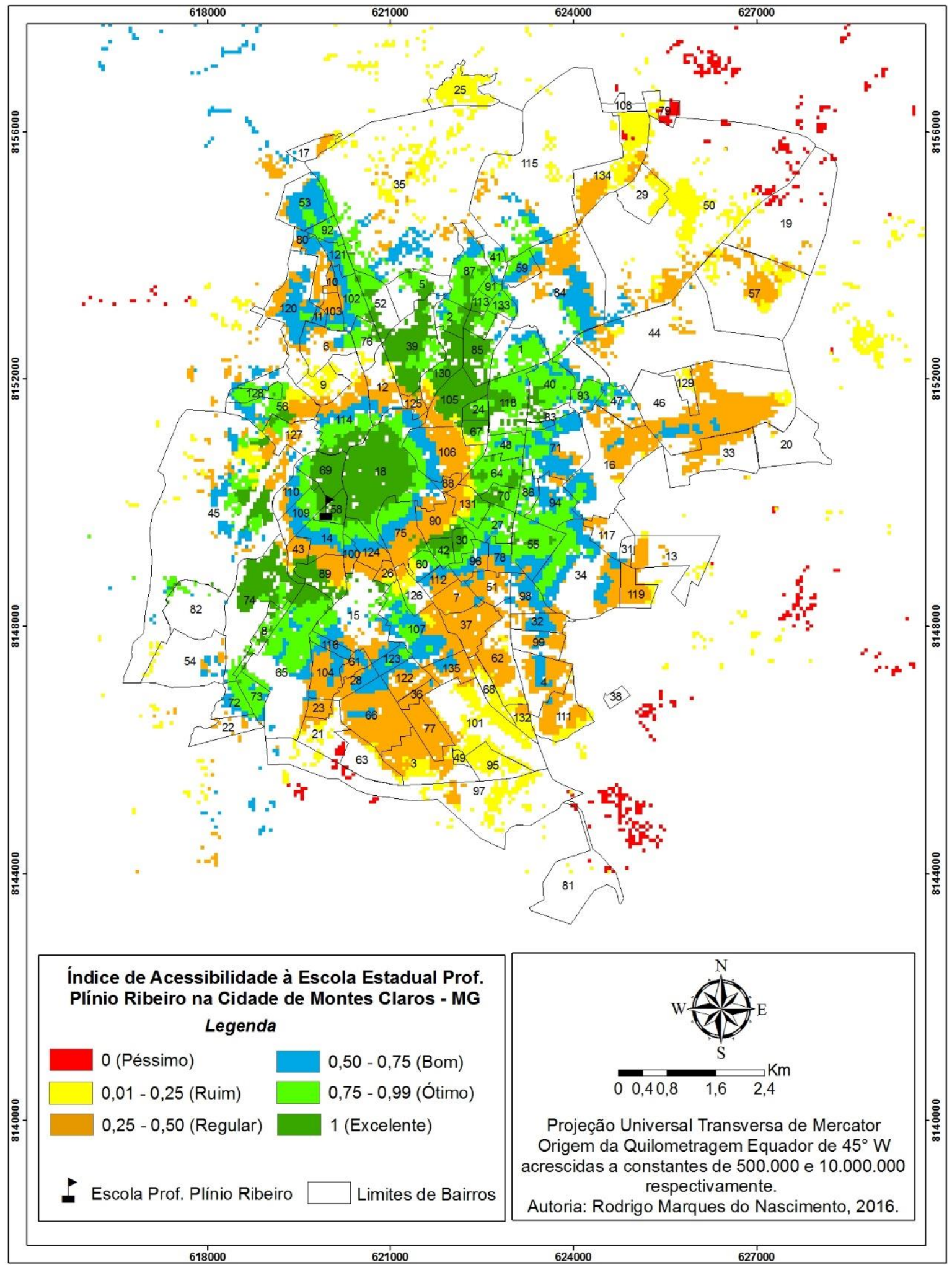

Fonte: Autoria própria 
SANTOS NETO, N. F.; NASCIMENTO, R. M.; TEIXEIRA FILHO, J. L. L.

Análise da acessibilidade da população da cidade de Montes Claros/MM à uma escola pública por transporte coletivo

\section{CONCLUSÃO}

Através da pesquisa, foi possível levantar alguns dados sobre o Transporte Público Coletivo na cidade de Montes Claros - MG. Observou-se que a cidade possui cinco linhas de ônibus com ligação direta a escola Estadual Plínio Ribeiro, quais sejam: 5801, 5802, 5803, 8201 e 1901. Conjuntamente analisadas, identificou-se um índice de acessibilidade dos moradores da cidade de Montes Claros a escola. A partir dessa análise, percebeu-se que o índice de acessibilidade predominante em cada bairro ou região era diretamente influenciado pelo nível de serviço do transporte público naquela localidade.

Esse índice, guardadas suas limitações de não analisar conforto e custo, pode ser um instrumento para nortear políticas de expansão e benfeitoria ao transporte público na cidade, no que diz respeito a elevar a acessibilidade dos moradores à escola Plínio Ribeiro e regiões adjacentes. Melhorar esse índice significa contribuir para uma cidade mais harmônica e que cumpre sua função social, uma vez que a finalidade de uma escola é nobre, promovendo conhecimento e educando milhares de crianças e adolescentes.

Por fim, nota-se por meio da mapa 3 que uma "mancha" considerável de bairros possuem acessibilidade por ônibus público coletivo à instituição Professor Plínio Ribeiro excelente ou boa, destacando a área central e a região Oeste e Leste de Montes claros. Os fatores fundamentais para tal são a localização, próxima ao centro e a quantidade de linhas com ligação direta bairro - centro que são cinco.

\section{REFERÊNCIAS}

ASSOCIAÇÃO BRASILEIRA DE NORMAS TÉCNICAS - ABNT. NBR_15570-20011_ Transporte - Especificações técnicas para fabricação de veículos de características urbanas para transporte coletivo de passageiros.

ASSOCIAÇÃO NACIONAL DOS TRANSPORTES PÚBLICOS - ANTP. Mobilidade, transporte público e o estatuto da cidade: desafios para um desenvolvimento sustentável. Texto apresentado no I Congresso nacional pelo Direito à Cidade, São Paulo. Associação nacional de Transportes públicos. São Paulo, 2001.

BARAT, Josef. Evolução dos transportes no Brasil. Rio de Janeiro: Fundação IBGE, 1978.

BRANCO, Gabriel Murgel. O Proconve: Alcance e dificuldades. In Secretaria do Meio Ambiente. Meio Ambiente e Transporte Urbano. São Paulo, 1990. 
SANTOS NETO, N. F.; NASCIMENTO, R. M.; TEIXEIRA FILHO, J. L. L.

Análise da acessibilidade da população da cidade de Montes Claros/MM à uma escola pública por transporte coletivo

BRASIL, Lei Federal no 10.257, de 10/07/2001: Regulamenta os artigos 182 e 183 da Constituição Federal, estabelece diretrizes gerais da política urbana (Estatuto da Cidade) e da outras providências. Disponível em:

<http://www.planalto.gov.br/ccivil_03/LEIS/LEIS_2001/L10257.htm>. Acesso em Maio de 2016.

BRASIL. Ministério das Cidades. PlanMob/Construindo uma Cidade Acessível. Caderno 2. Brasília: Ministério das Cidades, 2007. Disponível em:

<http://www.cidades.gov.br/images/stories/ArquivosSNH/ArquivosPDF/Livro-Plano-

Mobilidade.pdf $>$. Acesso em: 29 junho 2018.

BRASIL. Ministério das Cidades. 2007. Caderno PlanMob: para orientação aos órgãos gestores municipais na elaboração dos Planos Diretores de Mobilidade Urbana. Brasília.

BELTRÃO SPOSITO, M. E. O chão em pedaços: Urbanização, economia e cidades no Estado de São Paulo. UNESP, Presidente Prudente, 2004 (Livre Docência).

CARDOSO, L; Matos, R. Acessibilidade Urbana e Exclusão Social: novas Relações, velhos Desafios. In: X Simpósio Nacional de Geografia Urbana, Florianópolis, 2007.

FERRAZ, Antônio Clovis Pinto; TORRES; Isaac Guillermo Espinosa. Transporte Público Urbano. 2. ed. São Carlos: Rima, 2004.

GEIGER, P.P. Regionalização do espaço no Brasil. In: BARAT, Josef. Política de desenvolvimento urbano: aspectos metropolitanos e locais. 2. ed. Rio de Janeiro, IPEA/INPES, 1979.

JACOBS, Jane. Morte e vida de grandes cidades. São Paulo: Martins Fontes, 2001.

KOWARICK, L. Escritos Urbanos. São Paulo: Editora 34, 2000. 144p

Lei 10.257 de 10 de julho de 2001: Regulamenta os artigos 182 e 183 da Constituição Federal, estabelece diretrizes gerais da política urbana e dá outras providências. Brasília, 2001.

REDE IBERO-AMERICANA DE ESTUDO EM PÓLOS GERADORES DE TRÁFEGO (2008). Disponível em: http://redpgv.coppe.ufrj.br. Acesso dia 23/07/2016.

SIEBERT, Cláudia; SOUZA, Luiz Alberto de. Plano Diretor de Brusque: A participação da Universidade em sua revisão. COBRAC 98 - Congresso Brasileiro de Cadastro Técnico Multifinalitário. UFSC. Florianópolis. 18 a 22 de outubro de 1998.

VASCONCELLOS, Eduardo Alcântara. Transporte Urbano em países em desenvolvimento: Reflexões e Propostas. São Paulo. Annablume: 2000.

VAZ, J.C; Santoro, P. 2009. Cartilha Mobilidade urbana é desenvolvimento urbano! 2005. Disponível em: . Acesso em: 10 out. 2013. 
SANTOS NETO, N. F.; NASCIMENTO, R. M.; TEIXEIRA FILHO, J. L. L.

Análise da acessibilidade da população da cidade de Montes Claros/MM à uma escola pública por transporte coletivo

SANTOS NETO, Narciso Ferreira. Acessibilidade a Serviço de Saúde de Média

Complexidade por Transporte Público: Proposta de indicador. 2015. 239 f. Tese

(Doutorado em Engenharia de Transportes) Instituto Alberto Luiz Coimbra de Pós Graduação e Pesquisa de Engenharia -COPPE, Universidade Federal do Rio de Janeiro -UFRJ, Rio de Janeiro. 2015.

\section{Autores}

Narciso Ferreira dos Santos Neto - Possui Graduação em Engenharia Civil pela Fundação Educacional Minas Gerais (FEMG), Mestrado em Engenharia de Transportes pelo Instituto Militar de Engenharia (IME) e Doutorado em Engenharia de Transportes pela Universidade Federal do Rio de Janeiro (UFRJ). Atualmente é Professor na Universidade Estadual de Montes Claros (UNIMONTES).

Rodrigo Marques do Nascimento - Atualmente é Graduando em Engenharia Civil pela Universidade Estadual de Montes Claros (UNIMONTES).

José Luiz Lopes Teixeira Filho - Possui Graduação em Engenharia Civil pela Universidade Federal do Rio de Janeiro (UFRJ), Mestrado em Engenharia de Transportes pelo Instituto Militar de Engenharia (IME) e Doutorado em Engenharia de Transportes pela Universidade Federal do Rio de Janeiro (UFRJ). Atualmente é Professor na Universidade Federal de Juiz de Fora (UFJF).

Artigo recebido em: 25 de julho de 2017.

Artigo aceito em: 30 de junho de 2018.

Artigo publicado em: 30 de junho de 2018 . 